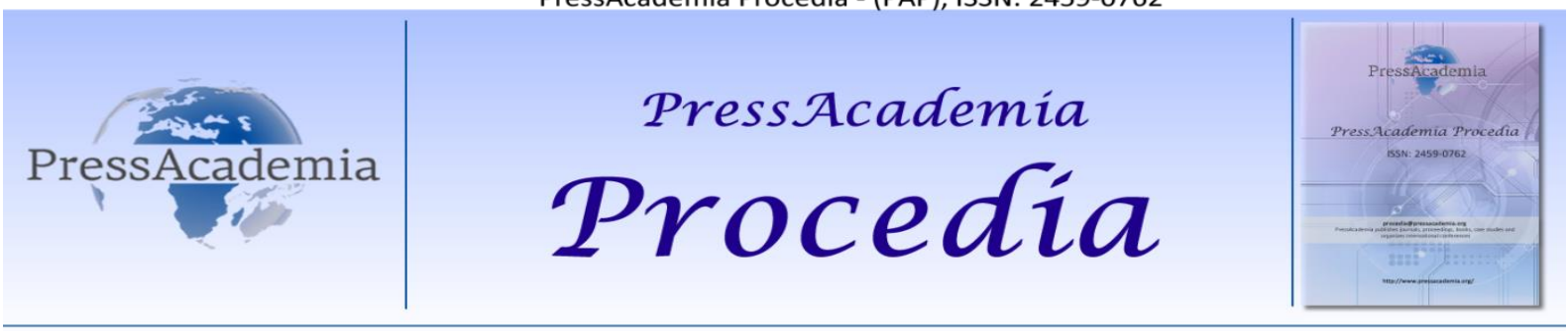

Global Business Research Congress (GBRC), May 24-25, 2017, Istanbul, Turkey.

\title{
THE RELATIONSHIP BETWEEN ORGANIZATIONAL LEARNING CAPABILITY, INTELLECTUAL CAPITAL AND JOB SATISFACTION IN SPORT ORGANIZATIONS
}

\author{
DOI: 10.17261/Pressacademia.2017.659 \\ PAP- GBRC-V.3-2017(85)-p.790-795
}

Umit Can Buyukakgul ${ }^{1}$, Metin Argan ${ }^{1}$

${ }^{1}$ Anadolu University, Eskisehir, Turkey, uc buyukakgul@anadolu.edu.tr

${ }^{1}$ Anadolu University, Eskisehir, Turkey, , margan@anadolu.edu.tr

To cite this document

Buyukakgul, U. C., M. Argan (2017). The relationship between organizational learning capability, intellectual capital and job satisfaction in sport organizations. PressAcademia Procedia (PAP), V.3, p.790-795.

Permemant link to this document: $h$ ttp://doi.org/10.17261/Pressacademia.2017.659

Copyright: Published by PressAcademia and limited licenced re-use rights only.

\begin{abstract}
The organizational learning capability of sport organizations is an important resource of being a learning organization. The effective and efficient management of this resource plays key role in the success of whole organization. Accurate assessment of the values which are created by the organizational learning process and evaluation of these values are necessary to make these values more efficient. The intellectual assets which are the results of organizational learning process are the most important resources of learning organizations. Positive and highly motivational climate created by these resources can inevitably affect performance of employees. In the light of these expectations first purpose of this research ise to identify organizational learning capability of sport organizations, and to explain the relationship between organizational learning capability and intellectual capital, and to assess effect of intellectual capital on job satisfaction. After conducting the analysis, it is found out that there are significant relationships between organizational learning capability factors -are commitment to learn, system perspective, openness and experimentation, knowledge transfer- and intellectual capital components. Also, as there are significant relationships between intellectual capital components which are human capital, structural capital and relational capital and job satisfaction but there is no significant relationship between organizational learning capability and job satisfaction. The other purpose of this research is to identify the employees' perceptions of organizational learning capability, intellectual capital and job satisfaction, and differentations of these perceptions by the demographic features, work experiment and instutions of participants. After conducting analysis, it has been reported that perceptions of organizational learning capability, intellectual capital and job satisfaction diffirentiate by monthly income and instutions of participants.
\end{abstract}

Keywords: Organizational Learning, Intellectual Capital, Job Satisfaction, Sport Organization

JEL Codes: D23, M12, L30

\section{SPOR ORGANIZASYONLARINDA ÖRGÜTSEL ÖĞRENME YETENEĞi, ENTELEKTÜEL SERMAYE VE iş TATMINi iLişKISi}

\section{ÖZET}

Spor organizasyonlarının sahip oldukları organizasyonel öğrenme yeteneği öğrenen bir organizasyon yaratmada önemli bir kaynaktır. Bu kaynağın etkili ve verimli bir şekilde yönetilmesi organizasyonun başarısında anahtar rol oynamaktadır. Organizasyonel öğrenme süreci sonunda ortaya çıkan değerlerin doğru anlaşılması ve gerektiğinde düzeltmelerin yapılarak daha etkili duruma getirilmesi organizasyonlar açısından bir gerekliliktir. Öğrenme süreci sonunda ortaya çıkan ve değer yaratan entelektüel varlıklar öğrenen organizasyonların en önemli kaynaklarıdır. Bu kaynakların yarattığı olumlu ve motivasyonel ortamın çalışanların performansına etki etmesi beklenen bir durumdur. Mevcut bu beklentiler ışığında bu çalışmanın ilk amacı; spor organizasyonlarının organizasyonel öğrenme yeteneklerini belirlemek, bu yeteneğin entelektüel sermaye ile olan ilişkisini açıklamak ve bu ilişkinin çalışanların iş tatmini düzeylerine etkisini ortaya koymaktır. Yapılan analizler sonucunda organizasyonel öğrenme yeteneği faktörleri olan öğrenme bağlıığı, sistem anlayışı, açıklık ve deneyleme ve bilgi transferi faktörlerinin entelektüel sermaye bileşenleri ile arasında anlamlı ilişkiler olduğu tespit edilmiştir. Ayrıca analizler sonucunda entelektüel sermaye bileşenleri olan insan sermayesi, yapısal sermaye ve ilişki sermayesi ile çalışanların iş tatmini seviyeleri arasında anlamlı ilişkiler tespit edilirken; organizasyonel öğrenme yeteneği ile iş tatmini arasında anlamlı ilişkiler tespit edilememiştir. Araştırmanın diğer amacı ise; katılımcıların organizasyonel öğrenme yeteneği, entelektüel sermaye ve iş tatmini algılarının demografik özellikler, deneyim süresi ve çalıştıkları kuruma göre farklılaşma durumunu belirlemektir. Bu doğrultuda yapılan analizler sonucunda, katılımcıların organizasyonel öğrenme yeteneği, entelektüel sermaye ve iş tatmini algıları aylık ortalama gelir düzeyleri ve çalıştıkları kuruma bağıı olarak farklılıklar gösterdiği tespit edilmiştir

Anahtar Kelimeler: Örgütsel Öğrenme, Entelektüel Sermaye, İş Tatmini, Spor Organizasyonu JEL Kodları: D23, M12, L30 


\section{GíRiş}

Organizasyonlar için yeni bilgilerin oluşturulması, paylaşılması ve kullanılması başarı için önemlidir. Başarı için ihtiyaç duyulan bu bilgilerin oluşturulmasında organizasyonların öğrenme yetenekleri ön plandadır. Öğrenmeye bağlı olmak, sistem anlayışı çerçevesinde öğrenmek, öğrenmeye karşı açık olmak ve deneylemekten kaçınmamak ve bilgiyi organizasyon içinde dağıtmak organizasyonların öğrenmesinde gerekli süreçlerdir. Bu süreçlerin doğru yönetilmesi öğrenme davranışının başarısına etki edecektir. Organizasyonel öğrenme süreci sonunda oluşturulan bilgiler rekabet ortamında başarıya giden yolda birer kaynak niteliğindedir. Organizasyonların bu kaynaklarının etin ve etkili kullanılması sonucu ortaya çıkan birikim entelektüel sermaye olarak adlandırılabilir. Entelektüel sermaye unsurlarının doğru ve net olarak ifade edilmesi organizasyonel öğrenme süreçlerinin etkin ve etkili şekilde yönetilmesine de etki edecektir. Bu bakımdan incelendiğinde organizasyonel öğrenme yeteneği ile entelektüel sermaye arasında güçlü bir ilişki olduğu söylenebilir. Ayrıca, bu güçlü ilişkinin çalışanların performansına da etki etmesi olağan bir durumdur. Çalışanların iş tatmini seviyeleri de onların performanslarının birer yansıması olarak kabul edilebilir.

\section{LITERATÜR INCELEMESI}

\section{Örgütsel Öğrenme}

Örgütsel öğrenme kavramı, organizasyonun içinde ve dışında meydana gelen değişikliklerin anlamlandırılması ve belirsizliklerin ortadan kaldırıması ihtiyacı ile birlikte gündeme gelmiştir. Buna bağlı olarak ortaya çıkan rekabet avantajı, yenilik yaratma ve kaliteyi arttırma gibi stratejik öneme sahip kavramlar da sürekli öğrenme ile ilişkilendirilmiştir (Rebelo ve Gomes, 2008). Örgütsel öğrenme, geçmiş deneyimlerin şuan ki ve gelecekteki davranışları etkilemesi (Levitt ve March, 1988), organizasyon içinde bilginin oluşturulması, saklanması, paylaşılması ve organizasyonun faaliyetlerinde kullanılması (Huber, 1991), organizasyonun sahip olduğu bilgi ve değerlerin gelişmesi ve buna bağlı olarak sorunlarla başa çıkma kapasitesinin gelişmesi (Probst ve Büchel, 1997), organizasyonların kendi sorunlarını çözmelerinde, yenilik yaratmada ve organizasyonun devamlılığını sağlamada ihtiyaç duyduğu en önemli yetenek (Chen vd., 2003)'tir.

Örgütsel öğrenme süreci dört aşamalı bir süreçtir (İstar, 2006 s.8). İlk aşamada bilginin elde edilmesi faaliyetleri yer alır. Bu aşamada, çalışanların sahip oldukları deneyim, tutum ve becerileri örgütlerin ilk bilgi kaynağını oluşturur (Arslantaş, 2003). Bunun dışında örgütlerin başarılı örgütlerden gözlem ve kıyaslama yoluyla elde ettikleri bilgiler de bu aşamada önemli yere sahiptir (Eren, 2004). Bu bilgiler ışı̆̆ından bilgilerin elde ediliş şekillerini iki şekilde ifade etmek yerinde olacaktır. İ̧̧ ve dış kaynaklar olarak kategorize edilebilecek bilgi elde etme yolları deneyimler, gözlemler, araştırmalar (iç kaynaklar), müşteriler, tedarikçiler, teknolojik ve ekonomik değişkenler (dış kaynaklar) olarak ifade edilebilir (Yazıcı, 2001). Örgütsel öğrenme sürecinin ikinci aşamasında, toplanan veriler örgüt içinde paylaşılır. Bu sürece verilen önem bilgilerin sağlıklı şekilde paylaşılmasına ortam sağlar (Çalık, 2010). Örgüt içinde yer alan bireylerin aktif şekilde öğrenme süreçlerine katılımı beraberinde bilginin etkili şekilde paylaşılmasını da getirir (Arslantaş, 2003). Örgüt içinde bilgiyi paylaşmanın birkaç yolundan söz edilebilir. Bunlar; network sistemleri, bilgisayarlar, programlar, uygulamalar, eğitimler, seminerler ve toplantı kayıtlarıdır (Şahinkesen, 2010). Örgütsel öğrenme sürecinin devam edebilmesi için toplanan ve paylaşılan bilginin bireyler tarafından içselleştirilmesi gerekir (Koç, 2006). Bu aşama bilginin kullanılmaya başlanmasından önceki en önemli süreçtir. İçselleştirilemeyen bilgilerin öğrenme sürecini sekteye uğratacağı düşünülebilir. Şahinkesen (2010)'in de belirttiği gibi bilgilerin içselleştirilmesi sadece bireylerin değil yöneticilerin de görevidir. Etkili ve açık bir iletişim ortamı yaratamayan yöneticiler fikirlerin ve bilgilerin paylaşılmasını da sağlayamaz. Örgütsel öğrenmenin son aşamasında içselleştirilen bilgilerin kullanılması süreci vardır. Bu aşamada önceden oluşturulan bilgiler yeni bilgilerin üretilmesinde kullanılır ve öğrenme süreci tekrar başa döner. Örgütsel öğrenme sürecinin sonunda elde edilen bilgiler daha sonra kullanılmak üzere örgütsel hafızada toplanır. Böylelikle örgütler örgütsel öğrenme süreci sonrasında örgütsel hafızada yer alan bilgiler sayesinde bir tutum geliştirebilirler.

\section{Entelektüel Sermaye}

Günümüz dünyasında küreselleşmeye ve bilgi temelli ekonomiye bağlı olarak bilginin yaratılması ve kullanılması örgütlerin sahip olduğu en önemli zenginlik kaynağı haline gelmiştir. Daha önceleri örgütlerin zenginlik yaratmada kullandıkları arazi, fabrika gibi sermaye varlıklarının yerini şimdilerde entelektüel sermaye varlıkları almıştır (Stewart, 1997). Entelektüel sermayenin sayısal olarak da ifade edilmesinde kullanılan ve defter değeri ile piyasa değeri arasındaki farkı ifade eden rakamlar entelektüel sermayenin çıkış noktasıdır (Seetharaman, 2002). Entelektüel sermaye bilgi ve yenilikçiliğin örgütlerin sürdürülebilir rekabet avantajı sağlamada başvurdukları faaliyetler olarak tanımlanabilir. Bilinen ilk entelektüel sermaye yönetici olan Edvinsson'a göre entelektüel sermaye bilgi, uygulamaya yönelik deneyim, örgütün sahip olduğu teknolojiler, müşteri ilişkileri ve mesleki yeteneklerin toplamı olarak tanımlamıştır (Edvinsson, 1997). Rakamlarla ifade edilmeye çalışılsa da entelektüel sermaye örgütte çalışanların kişisel ve sosyal birikimlerinin oluşturduğu görünmez değerlerdir (Sveiby, 2001). Fabrika, iş gücü, arazi gibi temel varlıklara kıyasla görünmez olan entelektüel sermaye varlıklarının tanımlanması, ölçülmesi ve yönetilmesi sürdürülebilir rekabet avantajı sağlamak isteyen örgütler için önemlidir. 
Bilginin ve maddi olmayan varlıkların örgütsel açıdan daha fazla önem kazanması, örgütlerin piyasa değeri ile defter değeri arasındaki farkın giderek artması entelektüel sermayenin de öneminin artmasına sebep olmuştur (Bozdemir, 2009). Nadir oldukları, gözlemlenemedikleri, taklit ve ikame edilemedikleri (Hall, 1992; Riahi-Belkaoui, 2003; Ghosh ve Wu, 2007) için entelektüel varlıklar örgütler açısından stratejik bir öneme sahiptirler. Görünmeyen varlıkların modern ekonominin temelinde yer almaya başlaması (Marr, 2007) sadece örgütleri değil ulusları da bilgi temelli entelektüel varlıklar hakkında daha fazla öğrenmeye yöneltmiştir (Chen, Cheng ve Hwang, 2005).

\section{İş Tatmini}

İşletmelerin hedeflediklerine ulaşabilmelerindeki en önemli ve dinamik unsurun çalışanları olduğunu söyleyebiliriz. Çalışanların beklentilerini karşılayan, ihtiyaçlarını zamanında eksiksiz sağlayabilen işletmeler çalışanları için gereken ortamı oluşturabilirler ve işlerini gerçek anlamda severek yapan çalışanlar yaratabilirler. Bunu yaratmada en önemli araçlardan biri iş tatminidir. Sevimli ve İşcan (2005)'ın da belirttiği gibi iş tatmini çalışanların işlerine yönelik tutum ve davranışlarının toplamıdır. Bir tutum olarak iş tatmini ise inançların, duygu ve düşüncelerin, davranışsal yönelimlerin toplamıdır (Sabuncuoğlu, 2009). İş tatmini işletmelerin üretkenliği ve başarısına doğrudan etki eder. Bunun yanında çalışanların fiziksel ve ruhsal sağlıklarını korumayı da hedefler (Terekli, 2010). İs tatmini dinamik bir yapıya sahiptir. Bu yüzden tek seferlik, geçici yaklaşımlar ile istenilen uzun süreli iş tatminini yaratmak neredeyse imkânsızdır. Ayrıca bu kavram sıradan yöntemler ve yaklaşımlar ile yönetilmeyecek kadar da önemlidir (Akıncı, 2002). İş tatmini kavramı işletmelerde hem bireysel hedefleri hem de işletme başarısını ilgilendiren bir kavram olduğundan; hem bireysel hem de organizasyonel faktörler tarafından etkilenebilir. Cinsiyet, yaş, tecrübe, kişilik ve eğitim seviyesi kavramları iş tatminini etkileyen bireysel faktörlerken (Cano ve Miller, 1992; Oshagbemi, 2000; Andres ve Grayson, 2002; Çalışkan, 2005), işin niteliği, ücret, yükselme olanakları, övülmek, yönetim tarzı, çalışma koşulları ve çalışma arkadaşları (Beehr vd., 2004; Gürüz ve Gürel, 2006; Özkalp ve Kırel, 2007; Bozkurt ve Bozkurt, 2008; Sabuncuoğlu, 2009) kavramları da iş tatminini etkileyen organizasyonel faktörlerdir.

\section{Örgütsel Öğrenme ve Entelektüel Sermaye}

Örgütler sahip oldukları entelektüel varlıkların yarattığı değeri anlamaya başladıktan sonra bu varlıklar hakkında daha fazla bilgi sahibi olmanın gerekliliğini de kavramaya başlamıştır. Boudreau ve Ramstad (2007) bu değişimin, insan kaynakları yaklaşımını da etkilediğini ifade etmektedir. Buna göre insan kaynakları yaklaşımı çalışanlarını yönetmek için onları memnun edecek hizmetler sunmaya dayanan ürün temelli bir yaklaşımdan, insanları etkileyen ve onlarla ilgili kararları iyileştirerek örgütün başarısını arttırmaya dayanan çözüm odaklı bir yaklaşıma evirilmiştir.

H1: Örgütsel öğrenme ile entelektüel sermaye arasında anlamlı bir ilişki vardır.

\section{Örgütsel Öğrenme ve İş Tatmini}

Öğrenen organizasyonların en önemli disiplinlerinden olan takım halinde öğrenme, bireyleri aynı takım içinde sürekli öğrenme davranışına teşvik eden bir yöntemdir. Basım, Şeşen ve Meydan (2009) yaptıkları çalışmada, aynı takım içinde yer alan ve sürekli öğrenme çabasında olan bireylerin, bilgilerin birimler arasında dağılmasında ve yenilikçi davranışların geliştirilmesinde önemli rol oynadıklarını ortaya koymuşlardır. Buna bağlı olarak takım içinde oluşan sinerji, yenilikçi yaklaşımı destekler. Değişimin ve yeniliklerin odağında olan çalışanların işlerine karşı daha tatminkâr olmaları beklenebilir.

H2: Örgütsel öğrenme ile iş tatmini arasında anlamlı bir ilişki vardır.

\section{Entelektüel Sermaye ve İş Tatmini}

Entelektüel sermayeyi genişletmek isteyen organizasyonların geliştirmek zorunda olduğu yeteneklerden biri yeniliği teşvik etmektir. McGuirk, Lenihan ve Hart (2015)'ın da desteklediği gibi çalışanların yenilikçi özellikleri işletmelerin rekabetçi avantaj sağlamasında en önemli unsurlardan biridir. Shipton ve ark. (2006)'nin iş tatmini ve organizasyonel yenilikçilik arasındaki ilişkiyi inceledikleri çalışmalarında; iş tatmininin yenilikçiliği yaratmada ve desteklemede hatırı sayılır bir etkisinin olduğunu; hatta yenilikçiliğe karşı olan direncin kırılmasında da önemli rol oynadığını belirtmişlerdir.

H3: Entelektüel sermaye ile iş tatmini arasında anlamlı bir ilişki vardır.

\section{VERI VE YÖNTEM}

Araştırmanın verileri, 2016 yılının Nisan ve Mayıs aylarında toplanmıştır. Araştırmanın örneklemini Eskişehir ve İzmir illerinde bulunan Gençlik Hizmetleri ve Spor il ve iliçe müdürlüklerinde çalışanlar ile yine aynı şehirlerin belediyelerin Gençlik Hizmetleri ve Spor Daire Başkanlıkları ile Belediye Spor Müdürlüklerinde çalışanlar oluşturmaktadır. Araştırmada Örgütsel Öğrenme Yeteneğini ölçmek için Jerez-Gomez ve ark. (2005) tarafından geliştirilen ve Okumuş (2013) tarafından türkçeye uyarlanan ölçek, entelektüel sermayeyi ölçmek için Mura ve Longo (2013) tarafından geliştirilen model ve iş tatminini ölçmek için Chalykoff ve Kochan (1989) tarafından geliştirilen dört ifade ve tek boyuttan oluşan ölçek kullanılmıştır. 
Veri toplamada anket yöntemine başvurulmuştur. Anketler yardımıyla toplanan veriler bilgisayar ortamında SPSS ve SPSS AMOS programı kullanılarak analiz edilmiştir. Ölçek niteliğindeki değişkenlerin güvenilirlik analizi uygulanmış ve Cronbach's Alpha katsayısına bakılmıştır. Ölçeklerde yer alan faktör yapılarının doğrulanması ve yapı geçerliliklerinin değerlendirilmesi için doğrudan doğrulayıcı faktör analizi (DFA) yönteminden yararlanılııştır. Entelektüel sermaye bileşenleri, organizasyonel öğrenme yeteneği ve iş tatminine ilişkin katıımcıların demografik özellikleri, hangi kurumda çalıştıkları ve kurumda kaç yıldır görev yaptıklarına göre farklılaşma durumunu belirleyebilmek için T-tesi ve tek yönlü varyans analizi (ANOVA) uygulanmıştır. Değişkenler arasındaki ilişkiyi incelemek içinse korelasyon ve regresyon analizlerinden faydalanılmıştır.

\section{BULGULAR VE TARTIŞMA}

Araştırmaya katılanların cinsiyet, yaş, medeni durum, eğitim durumu, aylık ortamala gelir düzeylerine, çalıştıkları kuruma ve deneyim sürelerine ait veriler incelendiğinde katılanların büyük çoğunluğu erkeklerden ve 31-40 yaş aralığında olanlardan oluşmaktadır. Katılımcıların eğitim düzeyleri incelendiğinde büyük çoğunluğun lisans mezunu olduğu ve aylık ortalama gelirlerinin 2000 TL'nin üzerinde olduğu görülmektedir. Araştırmaya katılanların büyük bir bölümünün iş deneyim süresi 5 yıl ve altındadır. Bu durumdan hareketle katılımcıların büyük çoğunluğunun genç yetişkinler olduğunu söyleyebiliriz. Buna bağlı olarak da öğrenmeye olan motivasyonlarının daha yüksek olması ve bu durumun çalışmanın amacına daha büyük oranda hizmet edeceği kabul edilebilir.

\section{Araştırma Modelinin YEM Değerleri}

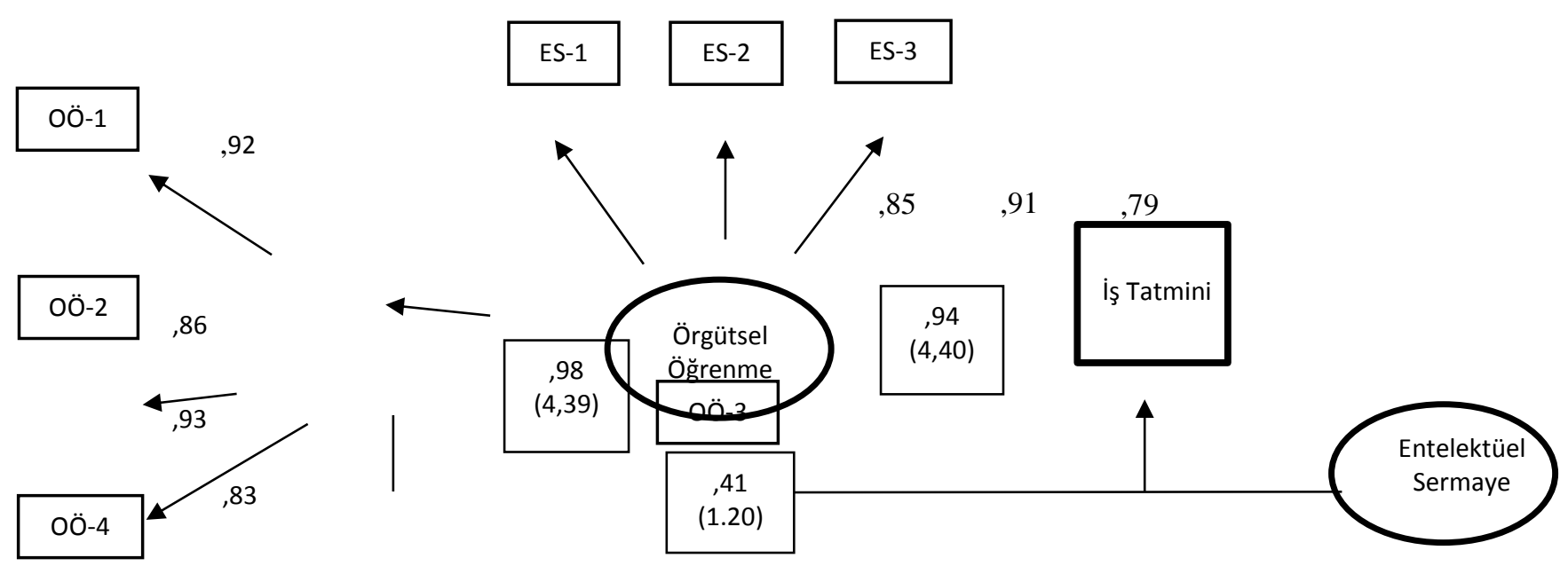

Uyum İstatistikleri: $\chi 2 / \mathrm{df}=3,30, \mathrm{CFI}=0.98, \mathrm{IFI}=0.98, \mathrm{NNFI}=0.97, \mathrm{RMSEA}=0.10 \mathrm{SRMR}=0.023, \mathrm{GFI}=0.94, \mathrm{AGFI}=0.87$

Not: parantez içindeki değerler $t$ değerlerini ifade etmektedir.

Yapılan YEM sonrasında $\mathrm{H} 1$ ve H3 hipotezleri kabul edilmiş, $\mathrm{H} 2$ hipotezi ise reddedilmiştir. Bu bilgiler ışığında örgütsel öğrenme ile entelektüel sermaye ve entelektüel sermaye ile iş tatmini arasında yüksek derecede anlamlı ilişki olduğu belirtilmiştir. Örgütsel öğrenme ile iş tatmini arasında ise bir ilişki olmadığı ifade edilmiştir.

\section{SONUÇ}

Bilginin oluşturulması ve yönetilmesi süreçleri ülkeler, organizasyonlar, üniversiteler, kamu kurum ve kuruluşları, işletmeler gibi birçok oluşumun başarısında önemlidir. Bu süreçlerin nasıl yönetildiği, ne kadar başarılı olunduğu ile doğru orantılıdır. Günümüzün bilgi temelli ekonomik düzeninde rakebet edebilmek, başarılı olabilmek ve sürdürülebilir sistemler oluşturmak için yeni bilgilere intiyaç vardır. Bu yüzden organizasyonların bu bilgiyi nasıl yaratttığının, organizasyon içinde nasıl paylaştığının ve bu bilgiyi nasıl bir sermaye unsuruna dönüştürdüğünün anlaşılması çok önemlidir. Ayrıca bu süreçlerin başarılı bir şekilde yönetilmesi sonucunda organizasyonların ne tür çıktılara sahip olacağının bilinmesi de organizasyonun sahip olduğu somut ve soyut bütün sermayelerin amaçlar doğrultusunda yönetilmesine yardımcı olacaktır. Bu bilgilere paralel şekilde çalışmanın sonunda örgütsel öğrenme yeteneği, entelektüel sermaye ve iş tatmini kavramları arasında çeşitli ilişkiler olduğu belirlenmiştir. Katılımcıların bu kavramlara ilişkin algılarının aylı ortalama gelir düzeyleri ve çalıştıkları kuruma göre farklııık gösterdiği tespit edilmiştir. 


\section{KAYNAKLAR}

Akıncı, Z. (2002). Turizm sektöründe işgören iş tatminini etkileyen faktörler: beş yıldızlı konaklama işletmelerinde bir uygulama. Akdeniz University Faculty of Economics \& Administrative Sciences Faculty Journal/Akdeniz Universitesi Iktisadi ve Idari Bilimler Fakultesi Dergisi, 2(4), p. 1-25.

Andres, L., Grayson, J. P. (2002, April). Educational Attainment, Occupational Status and Job Satisfaction: A Ten Year Portrait of Canadian Young Women and Men. In annual meeting of American Educational Research Association.

Arslantaş, C.C. (2003). Öğrenen Organizasyonlar ve Öğrenen Organizasyonlarda Örgüt İçi Bütünleşmeyi Etkileyen Unsurlara Yönelik Bir Araştırma, Doktora Tezi, İstanbul Üniversitesi, Sosyal Bilimler Enstitüsü, İstanbul.

Basım, N., Şeşen, H., Meydan, C. H. (2009). Öğrenen örgüt algısının örgüt içi girişimciliğe etkisi: kamuda bir araştırma. Ankara Üniversitesi SBF Dergisi, 64(03), 27-44.

Beehr, T. A., Nair, V. N., Gudanowski, D. M., Such, M. (2004). Perceptions of reasons for promotion of self and others. Human Relations, 57(4), 413-438.

Boudreau, J. W., Ramstad, P. M. (2007). Beyond HR: The new science of human capital. Harvard Business Press.

Bozdemir, N. Ö. (2009). Entelektüel sermayenin örgüt üzerindeki etkileri ve uygulamadan örnekler. Marmara Üniversitesi Sosyal Bilimler Enstitüsü Çalışma Ekonomisi ve Endüstri İlişkileri Anabilim Dalı, Yayınlanmamış Yüksek Lisans Tezi, İstanbul.

Bozkurt, Ö., \& Bozkurt, İ. (2008). İş tatminini etkileyen işletme içi faktörlerin eğitim sektörü açısından değerlendirilmesine yönelik bir alan araştırması.

Cano, J., \& Miller, G. (1992). A gender analysis of job satisfaction, job satisfier factors, and job dissatisfier factors of agricultural education teachers. Journal of agricultural education, 33(3), 40-46.

Chahal, H., Bakshi, P., (2016). Measurement of intellectual capital in the Indian banking sector. Vikalpa, vol. 41, no. 1, p. 61-73.

Chalykoff, J., \& Kochan, T. A. (1989). Computer-aided monitoring: its influence on employee job satisfaction and turnover. Personnel Psychology, 42(4), 807-834.

Chen, J. Q., Lee, T. E., Zhang, R., \& Zhang, Y. J. (2003). Systems requirements for organizational learning. Communications of the ACM, 46(12), 73-78.

Chen, M. C., Cheng, S. J., \& Hwang, Y. (2005). An empirical investigation of the relationship between intellectual capital and firms' market value and financial performance. Journal of intellectual capital, 6(2), 159-176.

Çalık, T. (2003). Öğrenen örgütler olarak eğitim kurumları. Manas Üniversitesi Sosyal Bilimler Dergisi, 8(2), 115-130.

Çalışkan, Z. (2005). İş tatmini: Malatya'da sağlık kuruluşları üzerine bir uygulama. Doğu Anadolu Bölgesi Araştırmaları, 3(1), 9-18.

Edvinsson, L. (1997). Developing intellectual capital at Skandia. Long range planning, 30(3), 320-373.

Eren, E. (2014). Örgütsel davranış ve yönetim psikolojisi. Beta Basım Yayım Dağıtım.

Ghosh, D., \& Wu, A. (2007). Intellectual capital and capital markets: additional evidence. Journal of Intellectual Capital, 8(2), 216-235.

Gürüz, D., \& Gürel, E. (2006). Yönetim ve organizasyon: Bireyden örgüte, fikirden eyleme. Nobel Yayın Dağıtım.

Hall, R. (1992). The strategic analysis of intangible resources. Strategic management journal, 13(2), 135-144.

Huber, G. P. (1991). Organizational learning: The contributing processes and the literatures. Organization science, 2(1), 88-115.

Koç, Ö. (2006). Öğrenen organizasyonlarda motivasyonun etkisi ve bir işletme uygulaması. Yayınlanmamış Yüksek Lisans Tezi. İnönü Üniversitesi, Sosyal Bilimler Enstitüsü, Malatya.

Levitt, B., \& March, J. G. (1988). Organizational learning. Annual review of sociology, 14(1), 319-338.

Marr, B. (2007). Measuring and managing intangible value drivers. Business Strategy Series, 8(3), 172-178.

McGuirk, H., Lenihan, H., \& Hart, M. (2015). Measuring the impact of innovative human capital on small firms' propensity to innovate. Research Policy, 44(4), 965-976.

Mura, M., \& Longo, M. (2013). Developing a tool for intellectual capital assessment: an individual-level perspective. Expert Systems, 30(5), 436-450.

Okumuş, K. (2013).Liderlik Tarzları, Örgütsel Öğrenme Yeteneği, Yenilik ve Firma Performansı İlişkisi, Yüksek Lisans Tezi, Gebze Yüksek Teknoloji Enstitüsü, Strateji Bilimi Anabilim Dalı, Gebze.

Oshagbemi, T. (2000). Gender differences in the job satisfaction of university teachers. Women in Management review, 15(7), $331-343$.

Özkalp, E., \& Korel, Ç. (2004). Örgütsel Davranış, Anadolu Üniversitesi Açıöğretim Fakültesi Yayınları, 2. Baskı, Eskişehir. 
Rebelo, T. M., Gomes, A. D., (2008). Organizational learning and the learning organization: reviewing evolution for prospecting the future, Learning Organization, 15(4), 294-308.

Probst, G., \& Büchel, B. S. (1997). Organizational learning: The competitive advantage of the future. Prentice Hall.

Riahi-Belkaoui, A. (2003). Intellectual capital and firm performance of US multinational firms: a study of the resource-based and stakeholder views. Journal of Intellectual capital, 4(2), 215-226.

Sabuncuoğlu, Z. (2009). Turizm işletmelerinde örgütsel davranış. MKM Yayınları.

Seetharaman, A., Helmi Bin Zaini Sooria, H., \& Saravanan, A. S. (2002). Intellectual capital accounting and reporting in the knowledge economy. Journal of Intellectual capital, 3(2), 128-148.

Sevimli, F., \& Iscan, Ö. F. (2005). Bireysel ve is ortamina ait etkenler acisindan is doyumu. Ege Academic Review, 5(1), 55-64.

Shipton, H. J., West, M. A., Parkes, C. L., Dawson, J. F., \& Patterson, M. G. (2006). When promoting positive feelings pays: Aggregate job satisfaction, work design features, and innovation in manufacturing organizations. European Journal of Work and Organizational Psychology, 15(4), 404-430.

Steward, T. A. (1997). Entelektüel sermaye: Örgütlerin yeni zenginliği. i̇stanbul: MESS yayınları.

Sveiby, K. E. (1997). The new organizational wealth: Managing \& measuring knowledge-based assets. Berrett-Koehler Publishers.

Şahinkesen, Ö. G. (2010). Öğrenen organizasyonlar Gaziosmanpaşa Üniversitesi'nde bir uygulama. Basılmamış Yüksek Lisans Tezi, Gaziosmanpaşa Üniversitesi, Sosyal Bilimler Enstitüsü, Tokat.

Terekli, G. (2010). Örgütsel Güven Boyutları Ve İ̧̧ Tatmini ilişsisi: Tekstil İşletmesinde Bir Araştırma. Anadolu Üniversitesi Sosyal Bilimler Enstitüsü, Yayınlanmamış Yüksek Lisans Tezi, Eskişehir.

Yazıcı, S. (2001). Öğrenen organizasyonlar. İstanbul: Alfa. 